\title{
303 Clinical Cases of the Gingival Regeneration in Periodontal Diseases
}

\author{
by \\ Masao KUSUNOKI, ${ }^{*}$ Shunro NAITO* and Noriko FUJISAKI*
}

\begin{abstract}
Introductory
Of the known means of cure for periodontal diseases, those of scaling and curettage are regarded as restorative or operative methods while gingivectomy and flap operation fall within the sphere of oral surgery. The latter try to remove the affected gingiva by surgical means so as to eliminate blind pockets but even the methods of gingivectomy and flap operation are measured its degree of successful cure in terms of native gingiva.

However, since 1952 a new means for this treatment has been succeedingly made public by such men as Goldmann [1], Schluger [1], Fox [1], OchsenBein [2], [3], Friedmann [4], Prichard [5] and Seibert [6] among others. Though fundamentally alike, the new method is published under various designations with certain changes in the operational procedures, such as the gingival replacement, gingival reattachment, gingival repositioning, gingival restoration, and gingival regeneration. These respective methods differ completely from any other means hitherto known in that they attempt at removing the whole native gingiva from around the periodontal region and produce entirely new gingiva on the exposed alveolar bone.

The authors connected with the Dental Hospital in Nihon University, Tokyo, Japan, have been applying the same method in their daily treatment of periodontal patients and the present report aims at presenting some of the interesting clinical findings.
\end{abstract}

\section{Periodontal Cases and Operational Procedure} patients.

This paper deals with the findings on the following number of periodontal

a. Number of cases treated.

$\begin{array}{ll}\text { Male patient } & 129 \text { cases } \\ \text { Female patients } & 174 \text { cases } \\ \text { Total } & 303 \text { cases }\end{array}$

b. Age groups

$\begin{array}{lr}\text { Under } 15 \text { yeare of age } & 7 \text { cases } \\ 16-20 \text { years of age } & 45 \text { cases } \\ 21-25 \text { years of age } & 107 \text { cases }\end{array}$

* 楠 正夫, 内藤 俊郎, 藤崎 笽子: Dept. of Periodontics, Nihon Univ. School of Dentistry. 
26-30 years of age

31-35 years of age

36-40 years of age

41-45 years of age

46-51 years of age

c. Affected regions.

$$
\frac{\frac{7-4}{3+3}}{\frac{4-7}{\overline{7-4} \mid}} \frac{\overline{3+3}}{4-7}
$$

52 cases

41 cases

22 cases

18 cases

12 cases

\section{0 cases}

64 cases

26 cases

25 cases

132 cases

27 cases

A
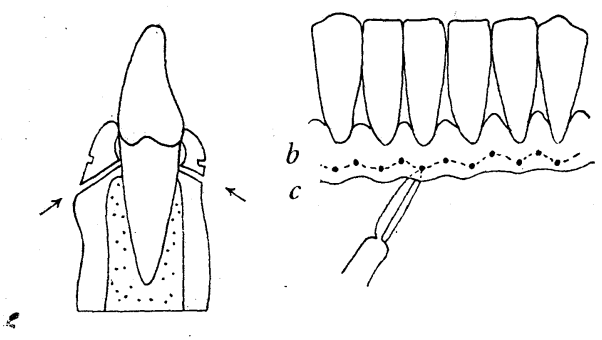

$b$. . . . . . .

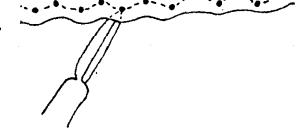

B
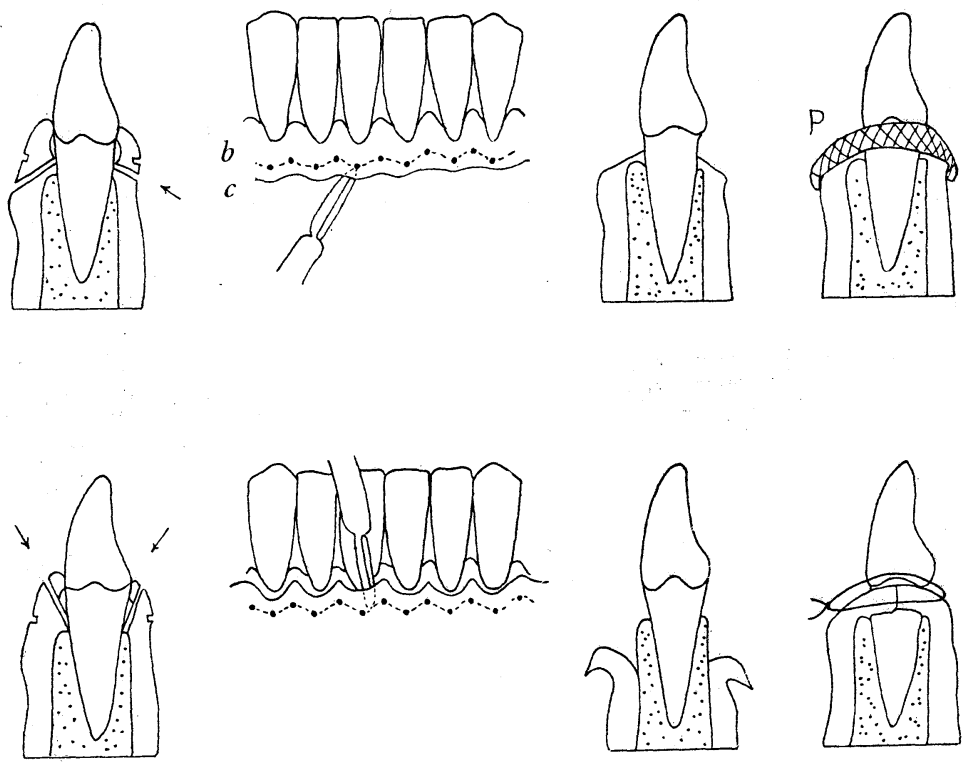

C

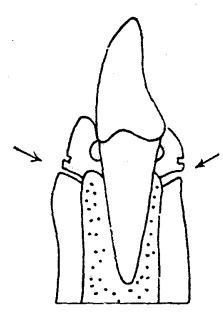

A: Curettage
$\mathrm{b}:$ Excision line $\mathrm{P}$

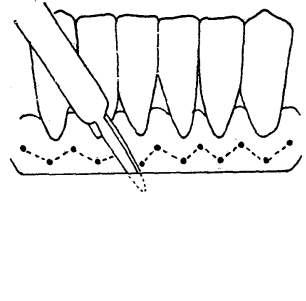

B : Gingivectomy C: Gingival regeneration method

Fig. 1
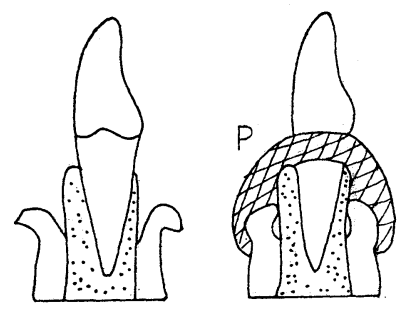
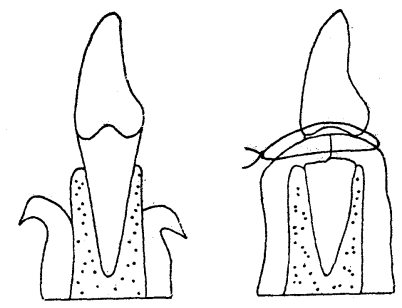
This operational procedure is found to have the following merits.

a. It is most fit for various stages of diseases from gingivitis hypertrophicans to alveolar pyorrhea and it is also applicable to cases where the resorption of alveolar bones advanced as far as two-thirds of the root.

b. When this method is compared with previous ones such as curettage and gingivectomy, it will appear as on Fig. 1.

c. It lends itself easily not only to the anterior region, but also to any other part of the dental arch.

\section{Conclusions and Considerations}

Based on our clinical records of 303 cases for whom the present method has been applied, we have arrived at the conclusions as follows.

1) This method is not to make use of native gingiva as is the case with previous methods of oral surgery, but by removal it tries to regenerate an entirely new mass of gingiva on alveolar bones.

2) It can be applied advantageously to any part of the dental arch.

3) Operational time is much reduced by this method since it does not require a surture as in flap operation.

4) It is possible to obtain a good result by removing and dressing part of the wall of pockets bone.

5) The use of splint should be recommendated in conjunction with this method as much as possible.

6) After one or two months of an operation, the margin of alveolar bones starts to be resorbed a little and this renders the teeth looser than the state prior to the operation. However, the growth of regenerated gingiva will restore the firmness of the teeth in time and for this reason a hasty extraction of the teeth should not be attempted.

7) This method does away with defects of Neumann's method in which it is not possible for the interdental papillary heads to be regenerated.

8) It may be advisable to apply this method to a case where an extraction of teeth is indicated at first sight.

9) The mechanism of gingival regeneration is not clear yet and we are being engaged in researches with animals to throw light on this matter. It is hoped that their findings may be published in not too distant future.

\section{References}

[1] Goldman, Schluger, Fox \& Cohn : Periodontal Therapy (1960).

[2] Ochsenbein, C. : Osseous Resection in Periodontal Surgery, J. Periodont., 28: 15 (January), 1958.

[ 3 ] OCHSENBEIN, C.: Newer Concepts of Mucogingival Surgery, J. Periodont., $31: 175$ (July), 1960.

[4] Friedman, N. : Periodontal Osseous Surgery, J. Periodont., 26 : 257 (Oct.), 1961.

[5] Prichard, J. F. : Gingivoplasty, Gingivectomy and Osseous Surgery, J. Periodont., 32 : 275 (Oct.), 1961.

[6] Serbert, J. S. : Technique for the Stabilization of Tissue Flap Employing Chrome-cobalt Alloy Tissue Tacks, J. Periodont., 32:283 (Oct.), 1961. 
Plate 1

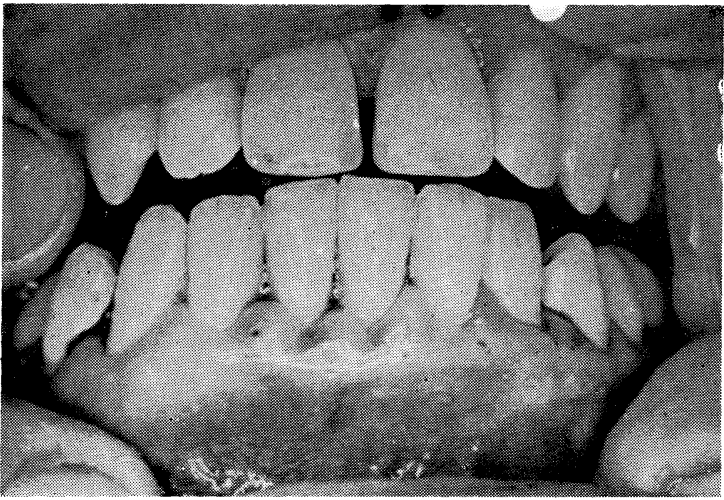

No. 1 Case 1

Anterior teeth before an operation.

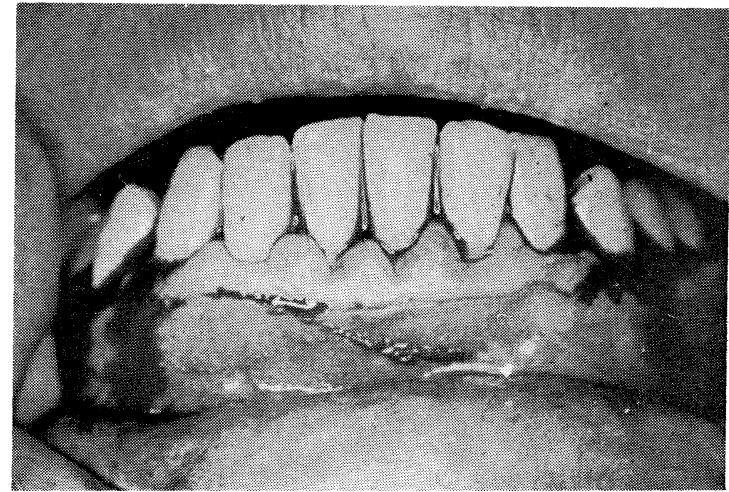

No. 2

A thick white line indicates attached gingiva.

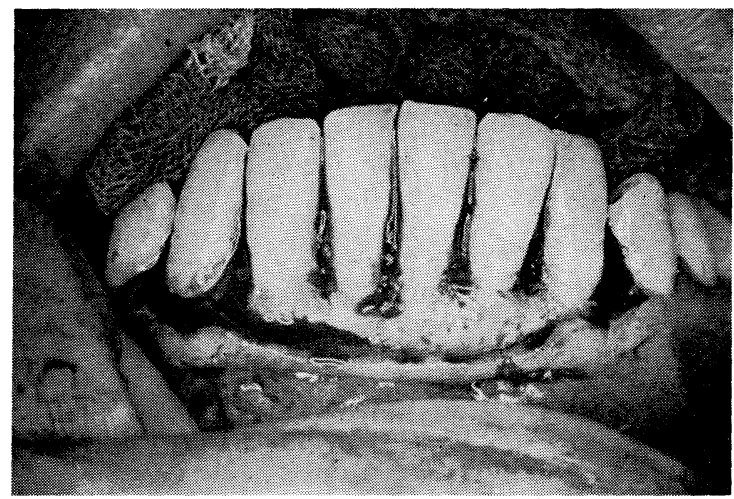

No. 3

After attached gingiva is excised, additional gingiva is removed to the depth of $3-4 \mathrm{~mm}$. Accretions on the gingiva are cleansed and osteoplasty effected.

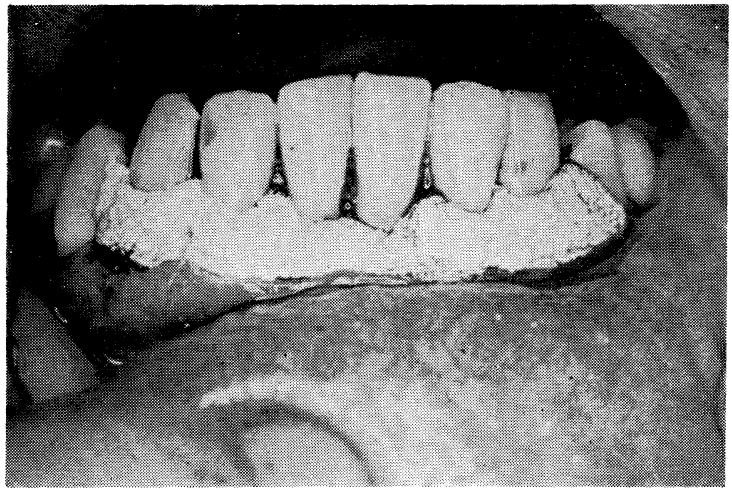

No. 4

Scaled gingiva is left where it is and a surgical pack is applied.

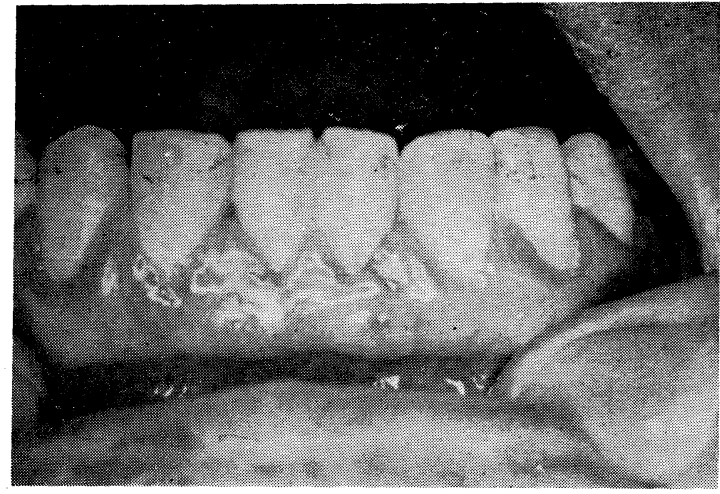

No. 5

A week after an operation. Regenerated gingiva assumes a vivid scarlet but it is not yet connected with the scaled gingiva. 


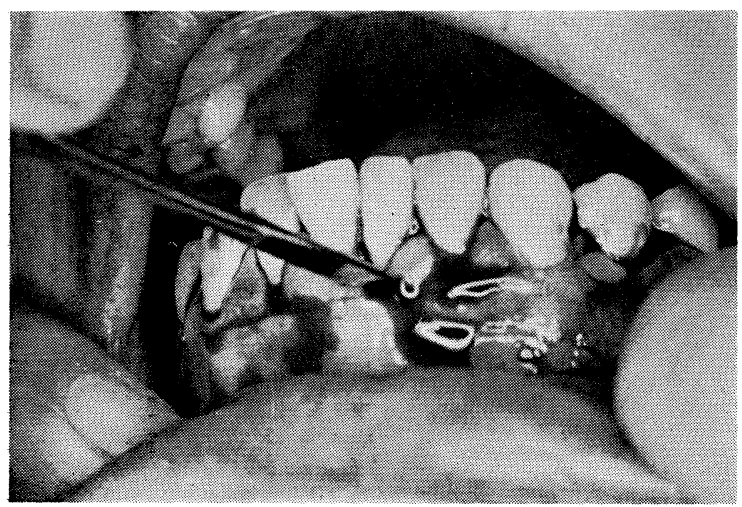

\section{No. 6 Case 2}

Attached gingiva is being excised (anterior region).

No. 7

After the complete excision of attached gingiva.
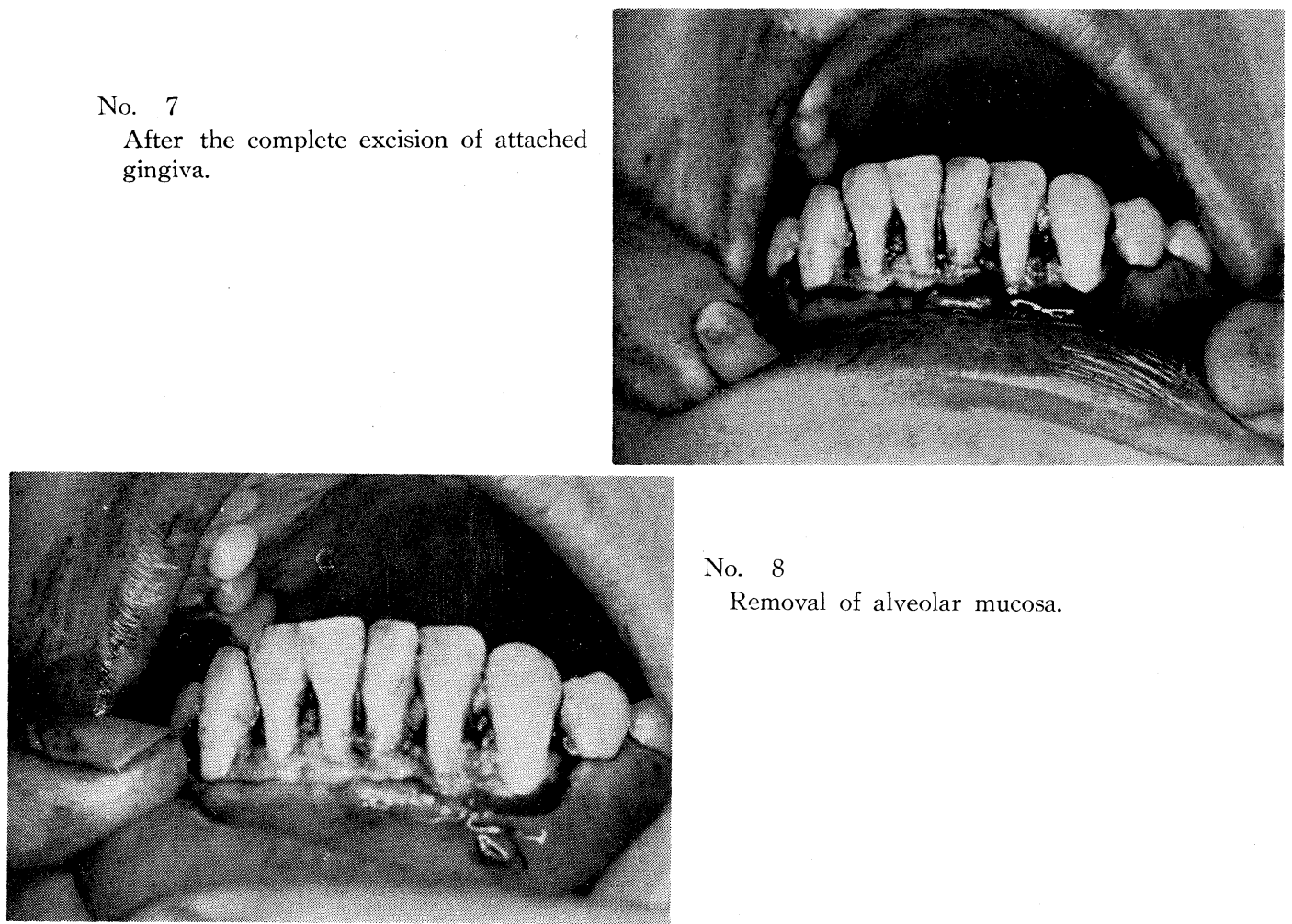

\section{No. 8}

Removal of alveolar mucosa.

No. 9

Cleansing of dental deposit on the gingiva and malign granulations.

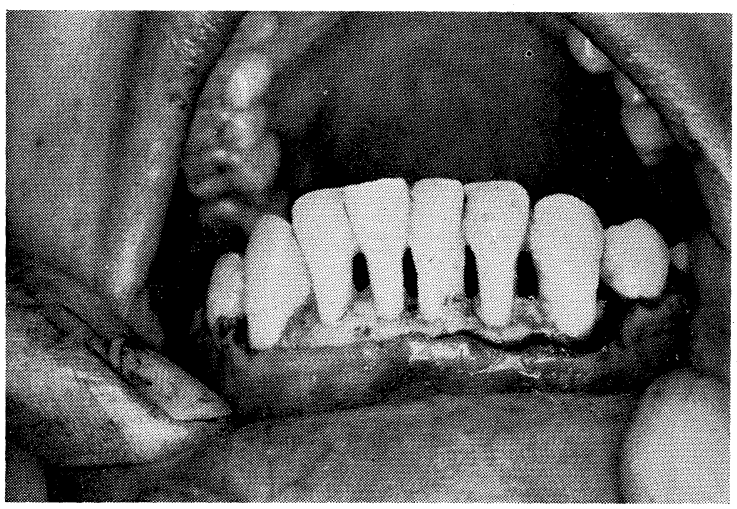




\section{Plate 3}

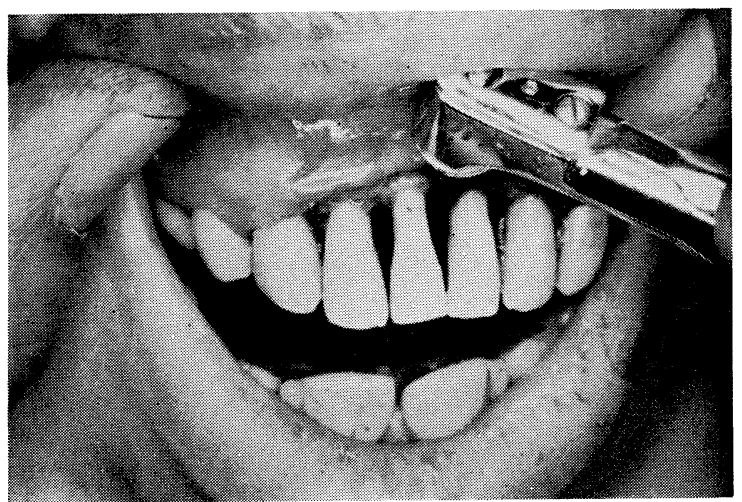

No. 10

Alveolar bone is better shaped by means of a diamond point. Anterior walls of pockets are being excised.

No. 11

A surgical pack is directly applied onto the exposed alveolar bone.
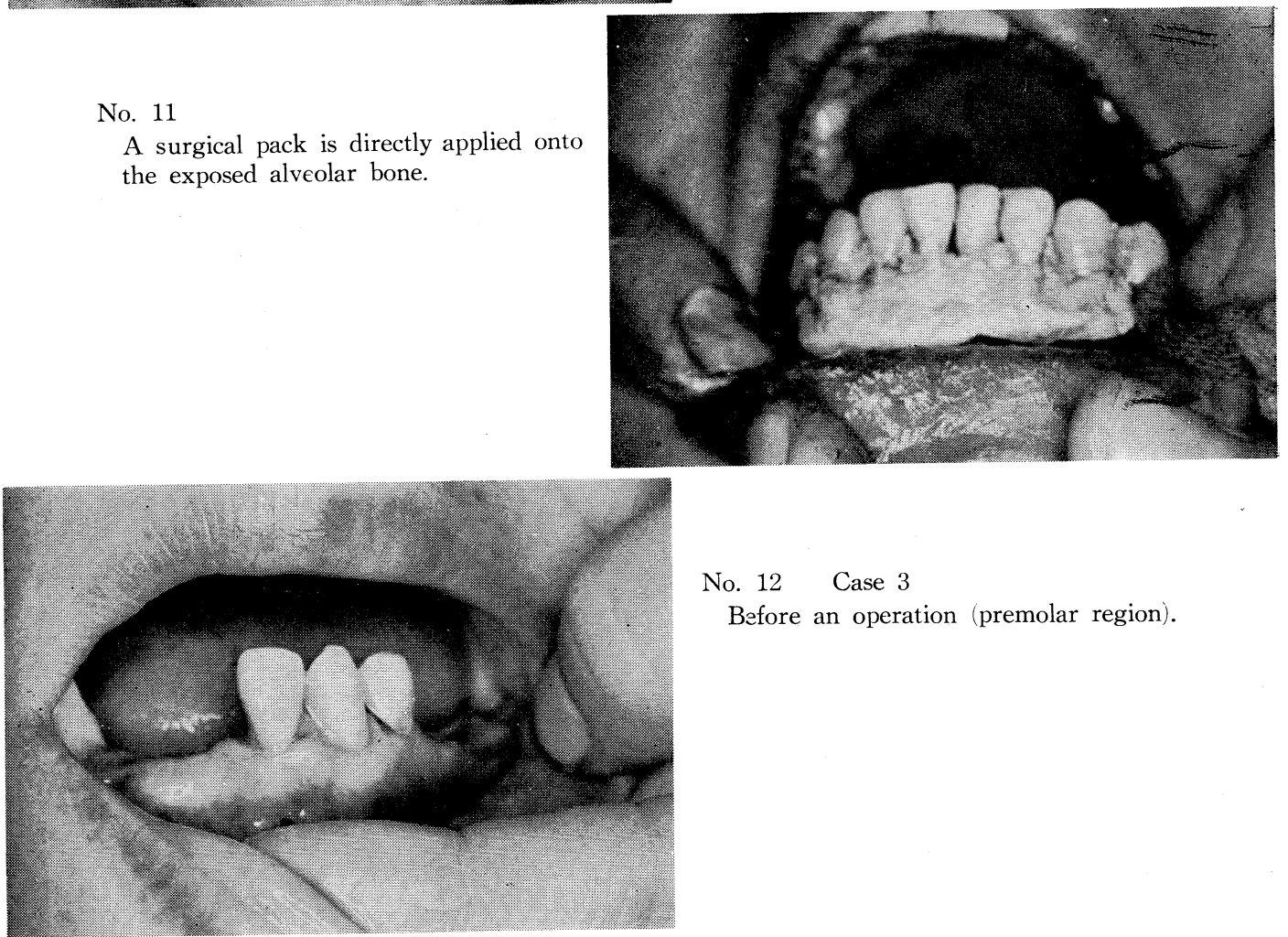

No. 12 Case 3

Before an operation (premolar region).

No. 13

A dotted line indicates where the attached gingiva is to be cut off.

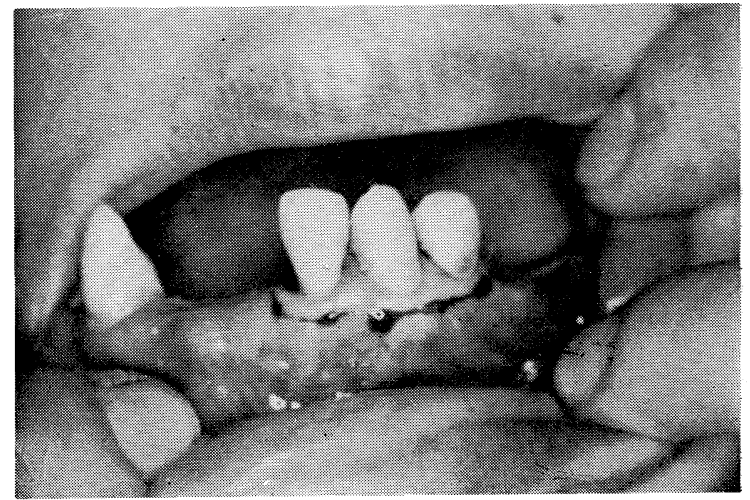


Plate 4

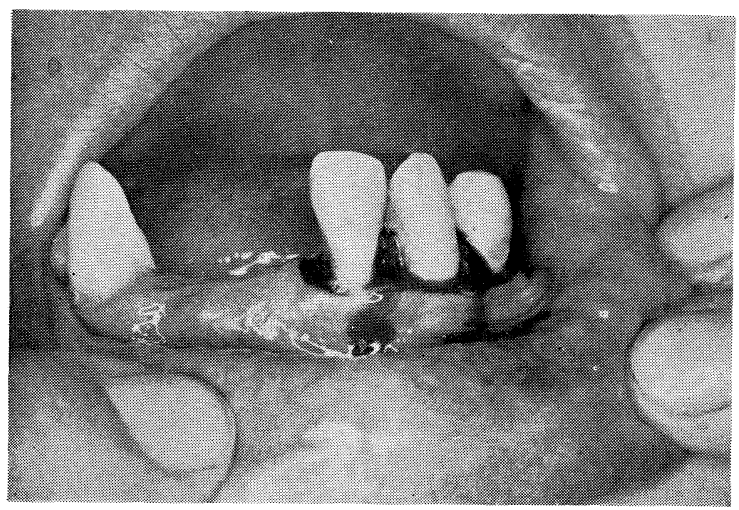

No. 14

Removal of attached gingiva.

No. 15

Removal of alveolar bone mucosa, cleansing and osteoplasty.
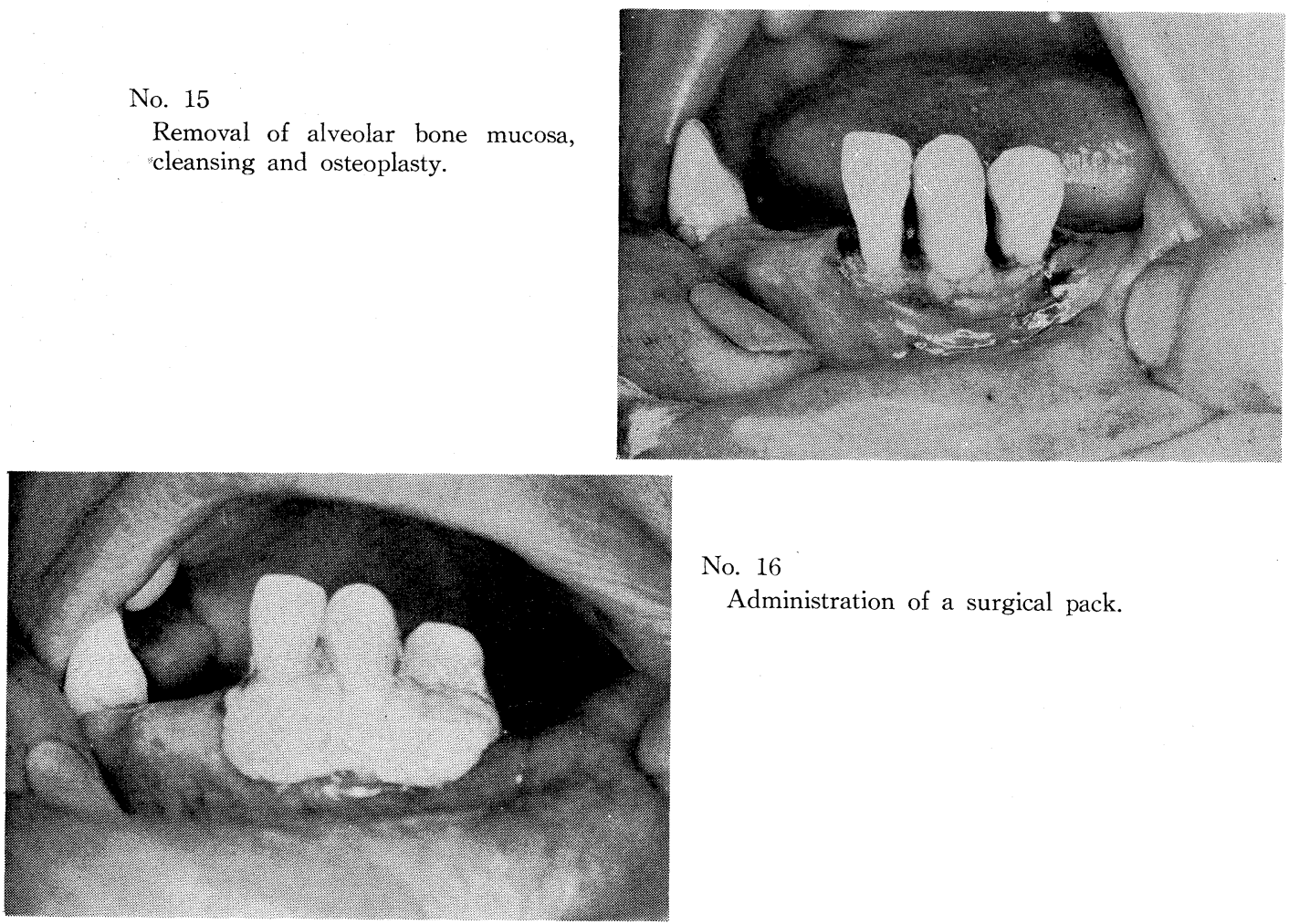

No. 16

Administration of a surgical pack.

No. 17

204th day after an operation. Healthy gingiva of pinkish tinge has been fully regenerated.

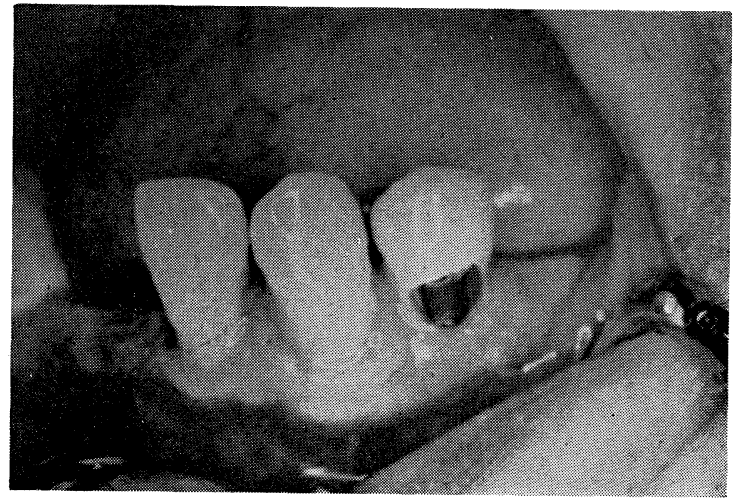




\section{Plate 5}

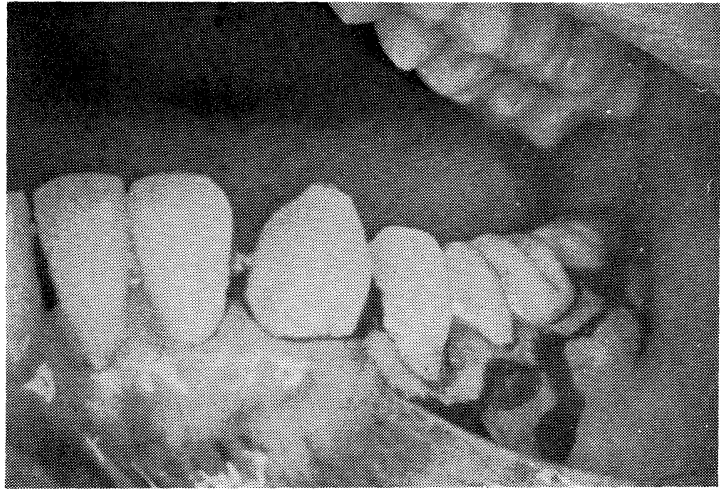

No. 18 Case 4

An excisive operation (molar region).

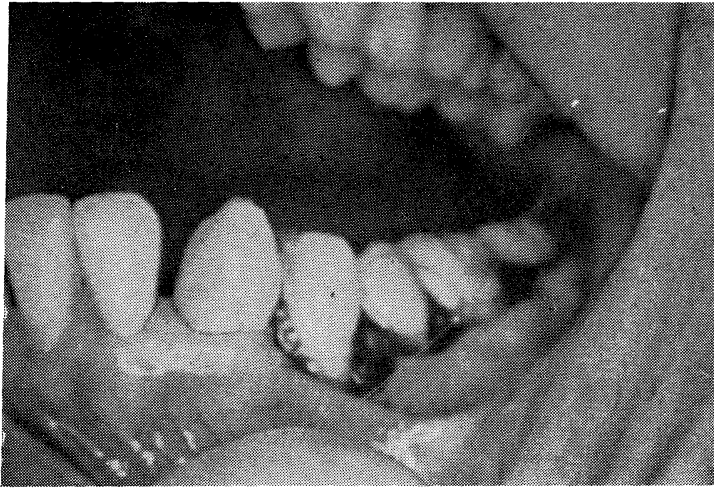

No. 19

Mucosa of alveolar bone is being removed. Many pathological granulations are noted.

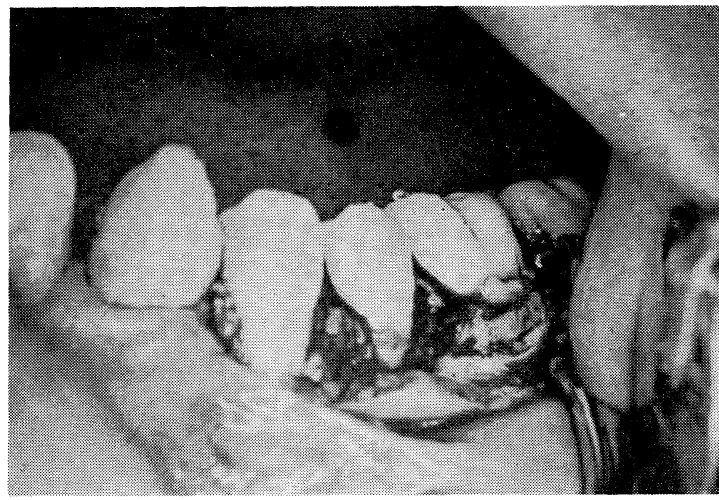

No. 20

Removal of attached gingiva.

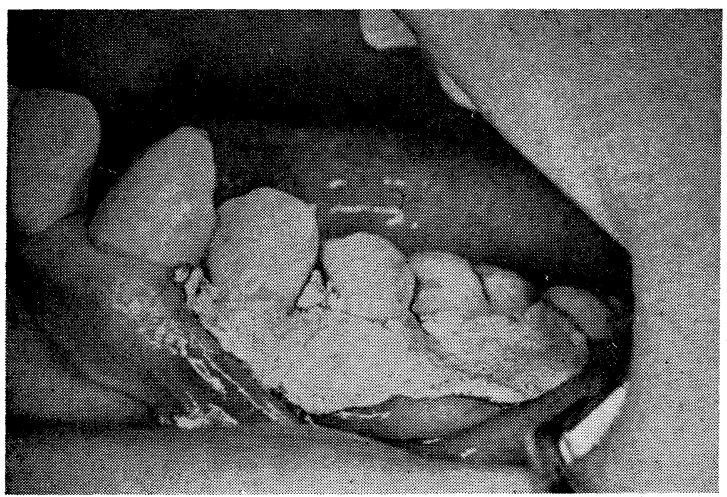

No. 21

Administration of a surgical pack.

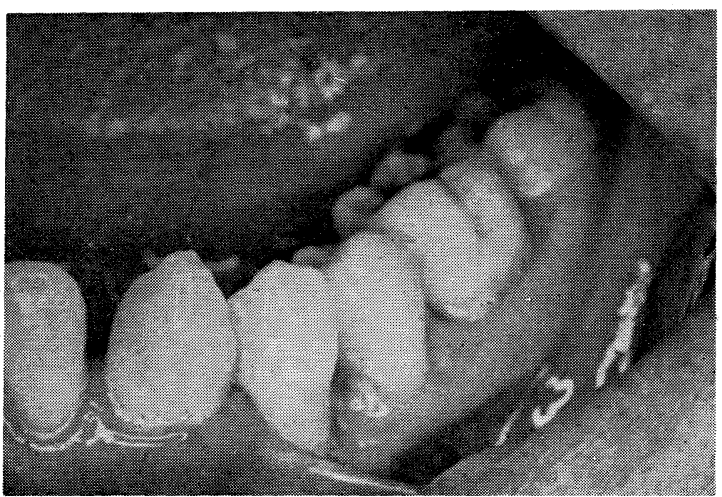

No. 22

Two weeks after an operation. Regenerated gingiva and native gingiva are perfectly merged. 


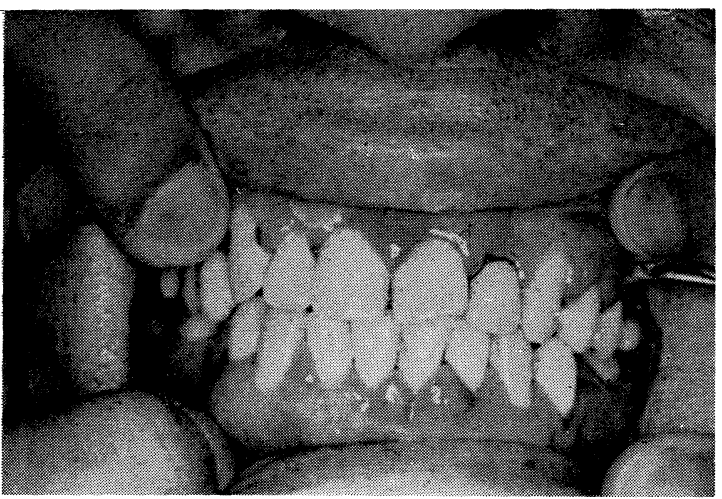

No. 23

Before an operation on a severe case of inflammatory gingival hyperplasia.

No. 24

Two weeks after the operation. Regenerated gingiva is still distinguishable from native gingiva.
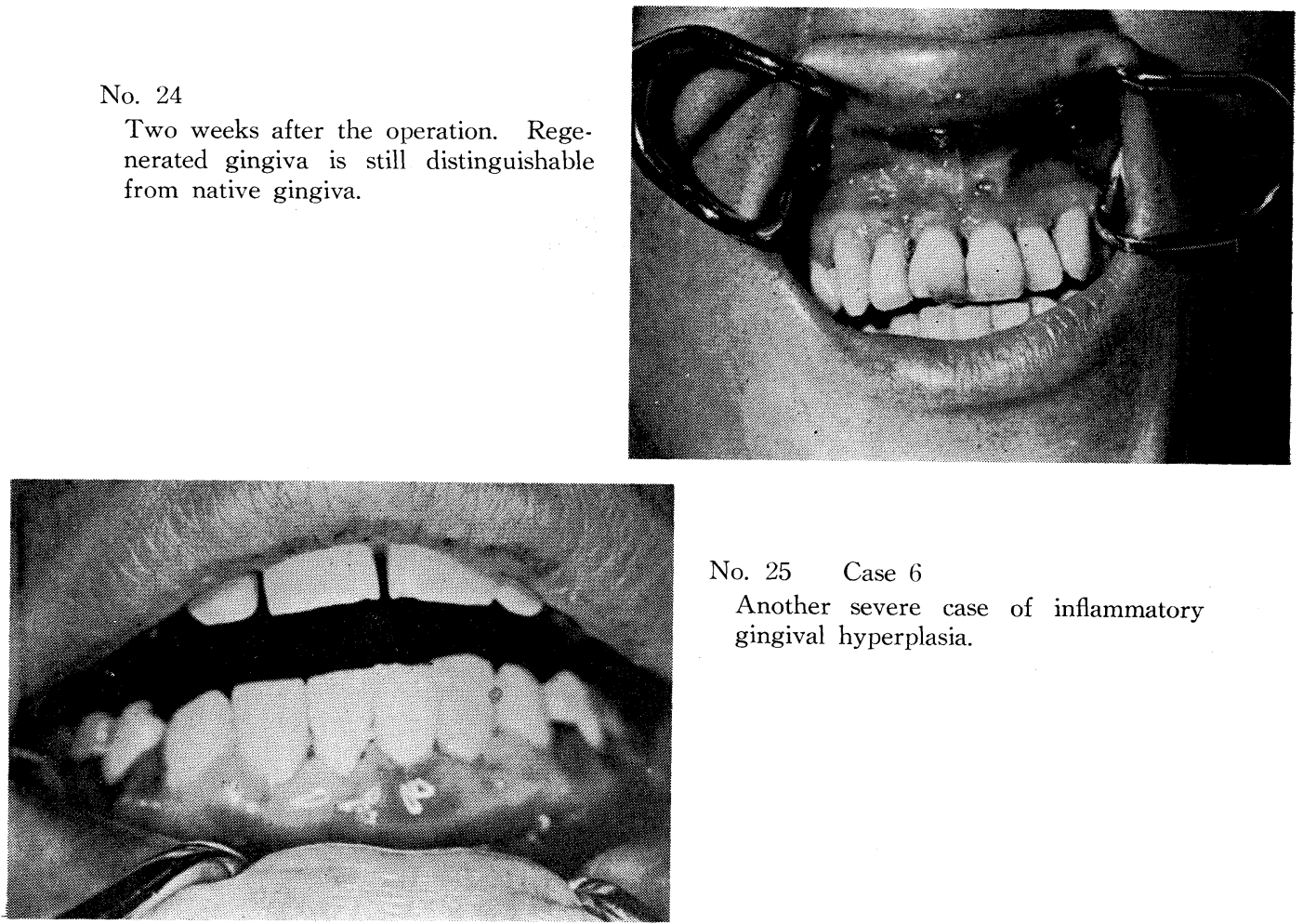

No. $25 \quad$ Case 6

Another severe case of inflammatory gingival hyperplasia.

No. 26

150th day after the operation. This illustrates a bad example of oral cleansing.

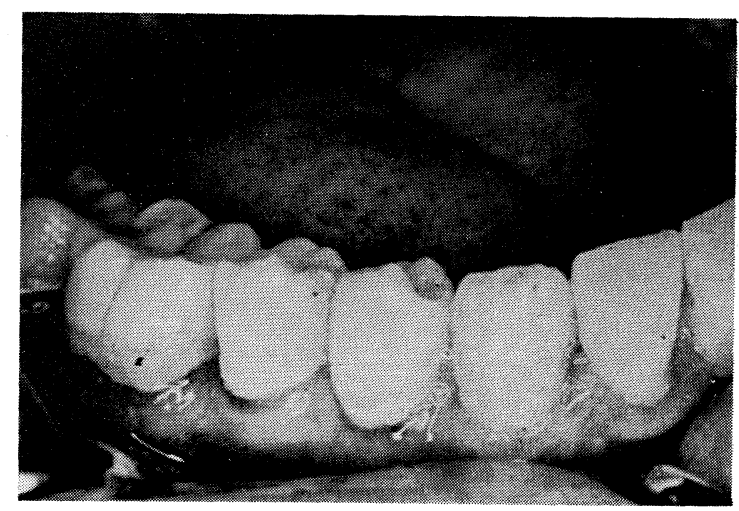




\section{Plate 7}

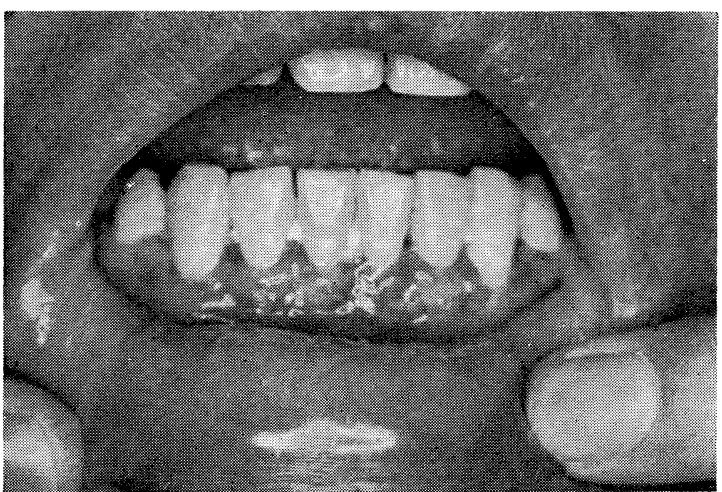

No. 27

A case of proliferative gingivitis. One week after the operation.

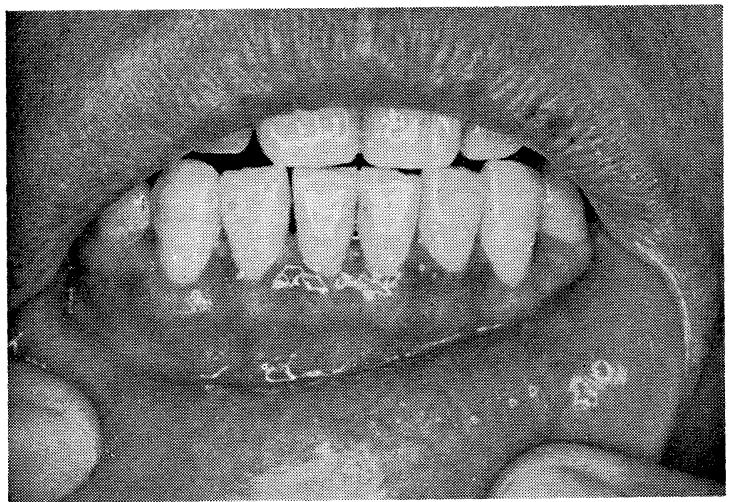

No. 28

The condition on the 13th day after the operation

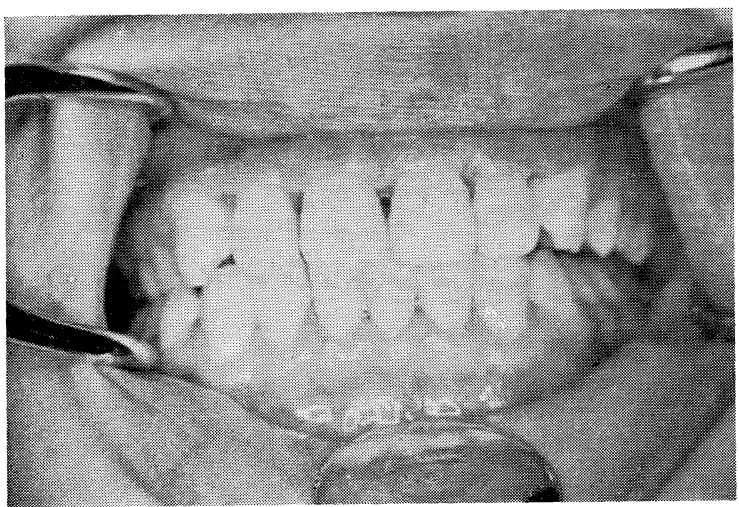

No. 29

One month after the operation. Neumann method was already applied to the upper jaw. 


\section{Plate 8}

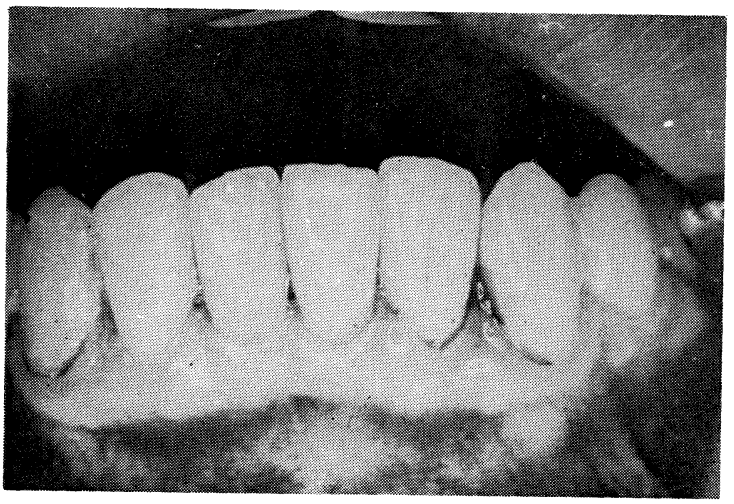

No. 30

79th day after the operation.

No. 31

85th day after the operation.
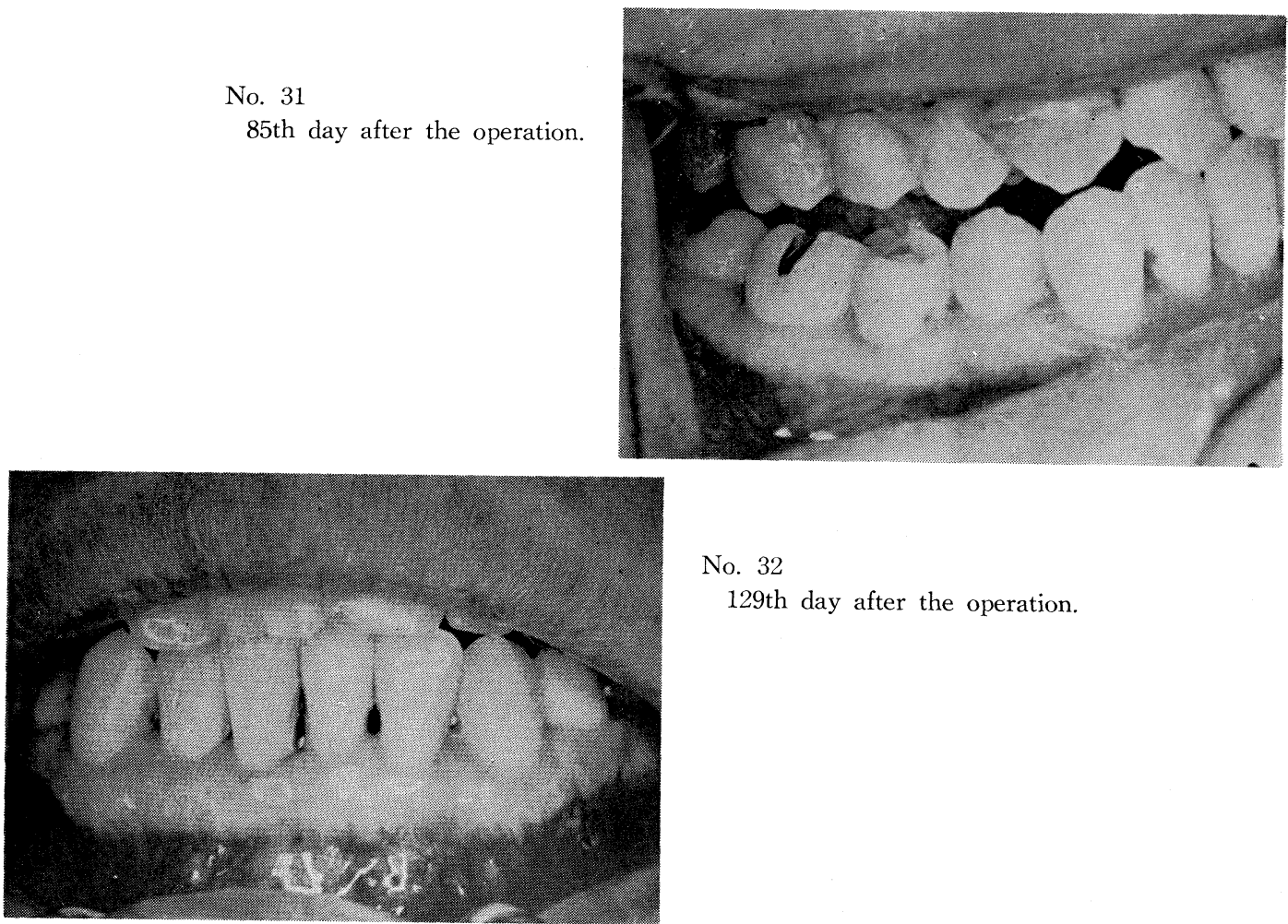

No. 32

129th day after the operation.

No. 33

A case of alveolar pyorrhea of severe degree. A ligature wire and resin fastener are temporarily used. This shows the condition on the 156th day after the operation.

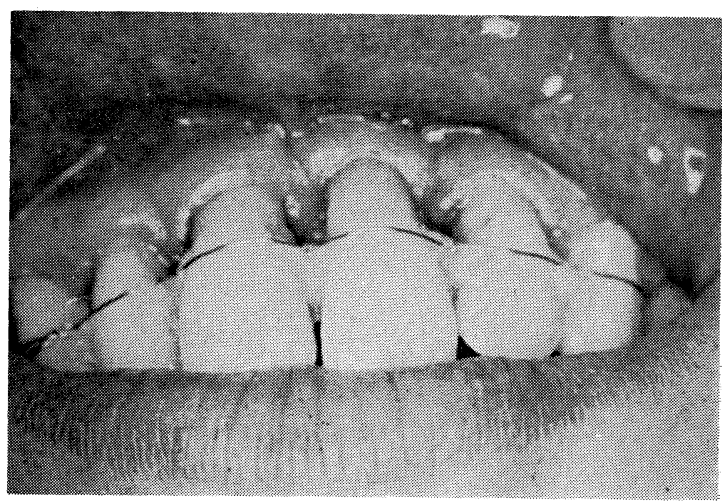


Plate 9

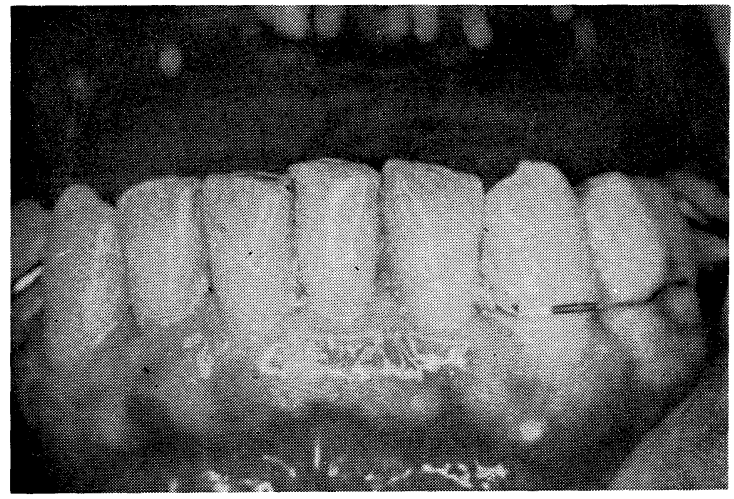

No. 34

199th day after the operation. Molars are fastened in place by means of a ligature wire.

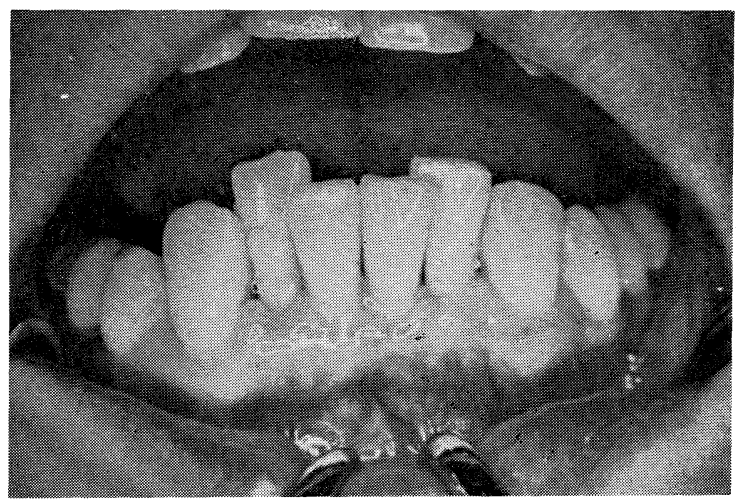

No. 35

217 th day after the operation.

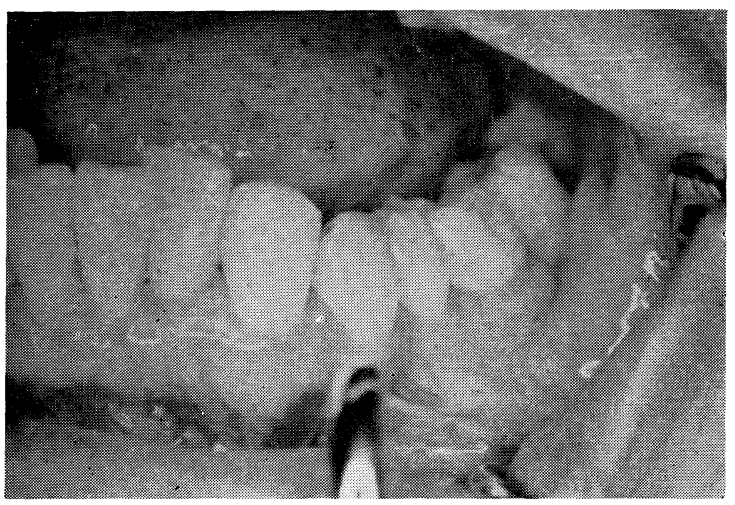

No. 36

229th day after the operation. This illustrates a case of defective alignment of teeth. 
Plate 10

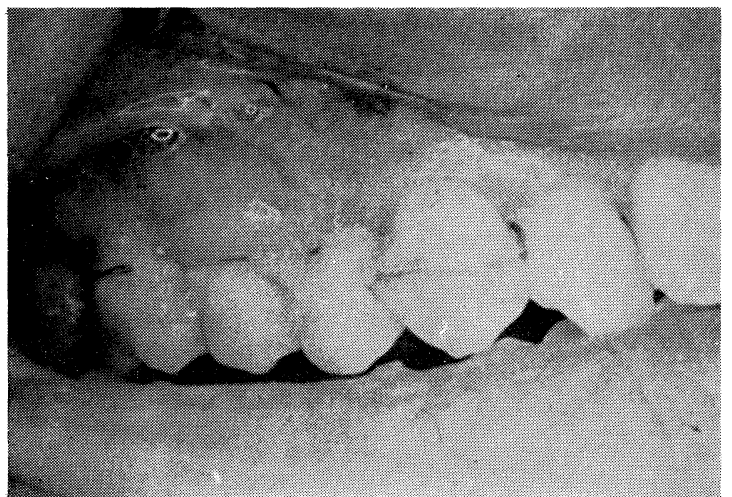

No. 37

Conditions on the 173rd day after the operation. A lingual metal plate, ligature wire and resin fastener are temporarily employed.

No. 38

A roentgenogram of the above case prior to an operation. Perpendicular resorption of 6 ] and 4] alveolar bones is remarkable.
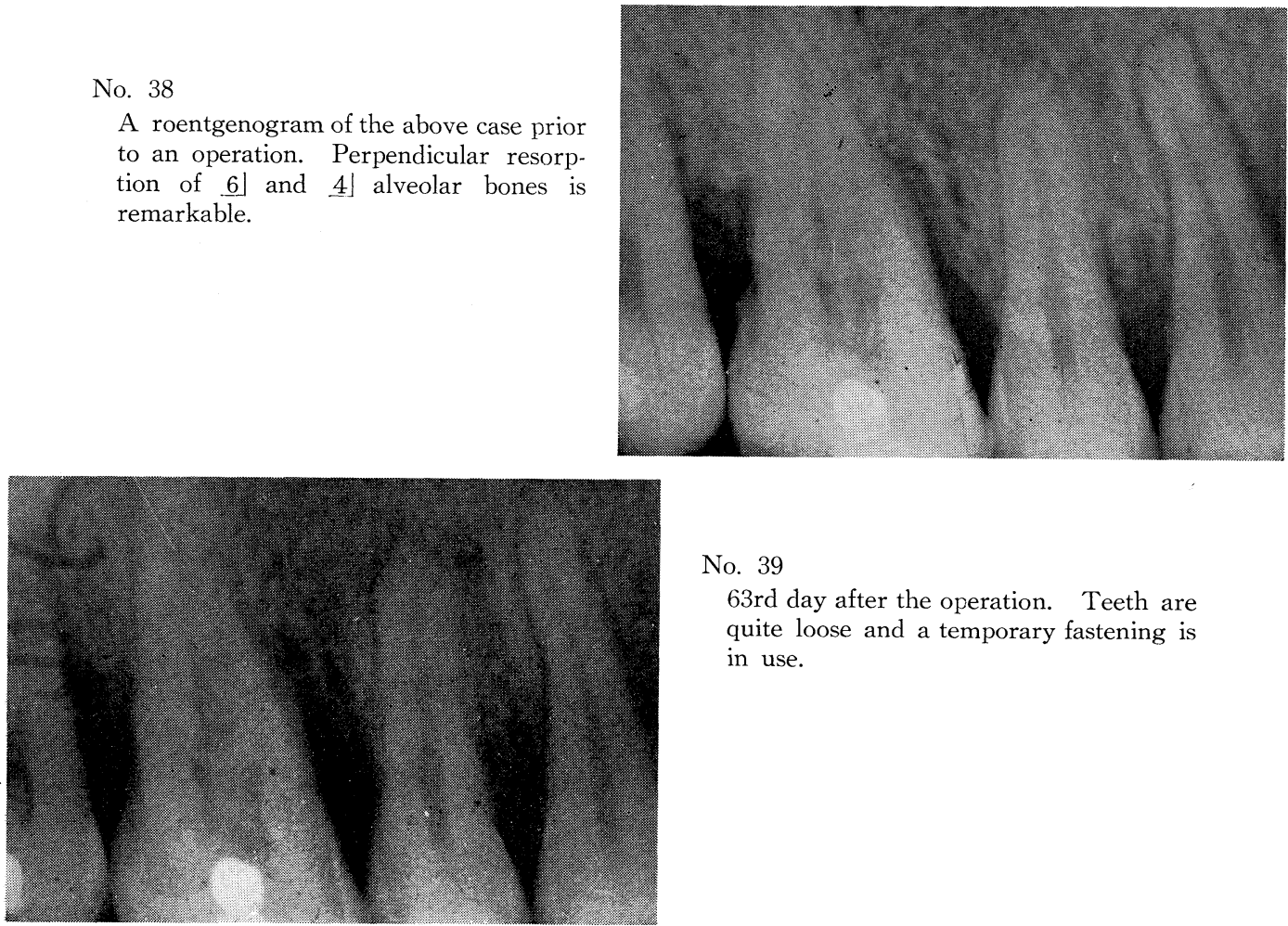

\section{No. 39}

63rd day after the operation. Teeth are quite loose and a temporary fastening is in use.

No. 40

173rd day after the operation. Regeneration of alveolar bones begins and teeth are loose to a lesser degree

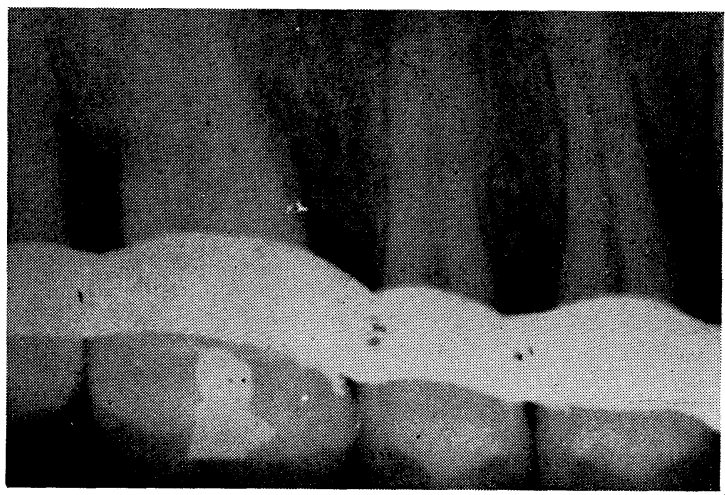

